\title{
Effect of Ethanol Extracts of Three Chinese Medicinal Plants With Anti-diarrheal Properties on Ion Transport of the Rat Intestinal Epithelia
}

\author{
Jong-Chang Tsai ${ }^{1}$, Shuli Tsai ${ }^{2}$, and Weng-Cheng Chang ${ }^{2,3, *}$ \\ ${ }^{I}$ Department of Physical Education, National Changhua University of Education, Changhua, Taiwan \\ ${ }^{2}$ Department of Physiology, ${ }^{3}$ Department of Sports Medicine, School of Medicine, China Medical University, \\ 91 Hsueh-Shih Road, Taichung, Taiwan
}

Received April 24, 2003; Accepted December 1, 2003

\begin{abstract}
Effects of ethanol extracts of three Chinese medicinal plants, namely, Qinpi (Fraxini cortex), Kushen (Sophora flavescens, AITON), and Huanglian (Coptis teeta, WALlicH), on ion transport of the rat intestinal epithelia were determined in this study. Rat intestinal epithelia mounted in an Ussing chamber attached to a voltage/current clamp were used for measuring changes in the short circuit current across the epithelia. Activation of the intestinal epithelia by serosal administration of $5 \mu \mathrm{M}$ forskolin resulted in an increase in basal short circuit current. The ethanol extracts of each of the three plants partially reduced the current stimulated by forskolin. In the following experiments, ouabain and bumetanide were added prior to adding the ethanol extract of these plants for revealing their effect on $\mathrm{Na}^{+}$and $\mathrm{Cl}^{-}$movement. The results suggest that the ethanol extract of the Qinpi would affect $\mathrm{Cl}^{-}$transport. On the contrary, the ethanol extract of Kushen would affect $\mathrm{Na}^{+}$transport rather than $\mathrm{Cl}^{-}$movement. This study provides evidences that reveal the pharmacological mechanism of the Chinese plants with anti-diarrheal properties.
\end{abstract}

Keywords: Chinese medicinal plant, ion transport, intestinal epithelia, anti-diarrhea, Ussing chamber

\section{Introduction}

According to the Chinese medical literature, Qinpi (Fraxini cortex), Kushen (Sophora flavescens, AITON), and Huanglian (Coptis teeta, WALLICH) were used for healing certain types of diarrhea (1). Although these plants have been in use for a long period, little is known about their pharmacological mechanisms in detail.

The main etiological cause of diarrhea has been documented to be excess water secretion in the intestinal epithelia $(2-4)$. Water movement in the epithelia is driven by an osmotic gradient created by active ion transport. Typically, the epithelial cells absorb water by active $\mathrm{Na}^{+}$uptake that is powered by the $\mathrm{Na}^{+}-\mathrm{K}^{+}$ATPase on the serosal side and secrete water by the active pumping of $\mathrm{Cl}^{-}$out of the cells generated by the $\mathrm{Na}^{+}-\mathrm{K}^{+}$-

*Corresponding author (affiliation \#2). FAX: +886-4-22029001

E-mail: wcchang@mail.cmu.edu.tw
$2 \mathrm{Cl}^{-}$cotransporter on the serosal side (5-7). Changes in $\mathrm{Na}^{+}$or $\mathrm{Cl}^{-}$transport in the epithelial cells are commonly seen in many cases of diarrhea induced by virus or bacteria $(8-11)$.

For the detection of ion transport in epithelia, the Ussing chamber attached with voltage/current clamp has been used for measuring short circuit current across epithelial tissues for decades. Since ions are charged, movements of cation or anion across the epithelia generally create a potential difference between the mucosal and serosal sides of the epithelia (12). When the potential difference is clamped to zero by using the voltage-clamp equipment, a short circuit current generated by the ion movements across the epithelia can be recorded. Fluctuation of the short circuit current, therefore, reflects changes of ion transport across the epithelia (13).

The present study is aimed at discerning the effects of extracts from the three Chinese medicinal plants 
mentioned above on ion transport of the rat intestinal epithelia by using the Ussing chamber and the voltageclamp techniques. The results indicate that these plants' extract can affect either $\mathrm{Na}^{+}$or $\mathrm{Cl}^{-}$movement, respectively, in the rat intestinal epithelia.

\section{Materials and Methods}

\section{Preparation of the extracts for Chinese plants}

Dried Qinpi, Kushen, and Huanglian were purchased from the Chinese pharmacy of the China Medical College Hospital. Twenty grams of each dried material was dissolved in $200 \mathrm{ml}$ ethanol and heated to boil for $30 \mathrm{~min}$. The supernatants were then collected and concentrated by a vacuum evaporator (EYELA N-N Serias; Tokyo Rikakikai, Tokyo) until the volume was reduced to $5 \mathrm{ml}$ and were stored in a $-20^{\circ} \mathrm{C}$ refrigerator.

\section{Animals and tissue preparation}

Healthy male Sprague-Dawley (SD) rats were obtained from Laboratory Animal Breeding and Research Center of the National Science Council, Taipei, Taiwan. The rats were maintained under temperature control of $23^{\circ} \mathrm{C}$ and kept on a 12-h light-dark cycle, with diet and water supplied ad libitum. Rats weighing 250-300 g were selected and killed by exposure to ether. In each rat, several segments of 2-cm ileum, free of Peyer's patches, were immediately removed and washed in Kreb's solution. Intact and flat sheets of the ileal epithelia were prepared by cutting open along the mesenteric border, and the serosal and muscular layers were peeled away under a binocular microscope (13).

\section{The Ussing chamber}

The epithelia were mounted between the Ussing chambers (CHM6; W.P.I., Sarasota, FL, USA). The buffers were oxygenated continuously and maintained at $37^{\circ} \mathrm{C}$. An automatic voltage clamp (DVC1000, W.P.I.) corrected for fluid resistance between the potential difference sensing $\mathrm{Ag} / \mathrm{AgCl}$ electrodes. A second pair of $\mathrm{Ag} / \mathrm{AgCl}$ electrodes continuously monitored the short circuit current across the tissue. The bathing solution in the serosal and mucosal chamber was composed of $118 \mathrm{mM} \mathrm{NaCl}, 4.7 \mathrm{mM} \mathrm{KCl}, 2.5 \mathrm{mM} \mathrm{CaCl}_{2}$, $1.2 \mathrm{mM} \mathrm{NaH}_{2} \mathrm{PO}_{4}, 1.2 \mathrm{mM} \mathrm{MgSO}, 25 \mathrm{mM} \mathrm{NaHCO}$, and $11.1 \mathrm{mM}$ glucose, $\mathrm{pH}$ 7.4. These chemicals were purchased from Merck (Darmstadt, FRG). Both buffers were gassed with $95 \% \mathrm{O}_{2}-5 \% \mathrm{CO}_{2}$ before filling the chambers (12).

\section{Experimental procedure}

To show the effects of the extracts on short circuit current of the rat ileal epithelia, forskolin (Sigma,
St. Louis, MO, USA) was first added on the serosal side (final concentration of $5 \mu \mathrm{M}$ ) of the tissue. The current increased and was stable after 3-5 min. At $10 \mathrm{~min}$ after the addition of the forskolin, $25 \mu$ l ethanol extract of each medicinal plant was then added on the serosal side. Change in the short circuit current was recorded continuously during the experiment. Because ethanol extracts of the medicinal plants were used for the experiments, the effect of ethanol on the short circuit current of the rat ileal epithelia was discerned in another experiment. The result showed the short circuit current showed little change in three intestinal tissues after the addition of $25 \mu \mathrm{l}$ ethanol in the mucosal buffer $(10 \mathrm{ml})$. Hence the vehicle (ethanol) effect was small. To discern whether the movement of sodium or chloride is involved in the effects of extract on the short circuit current across the epithelia, ouabain (inhibitor of $\mathrm{Na}^{+}-\mathrm{K}^{+}$ATPase) (Sigma) or bumetanide (inhibitor of $\mathrm{Na}^{+}-\mathrm{K}^{+}-2 \mathrm{Cl}^{-}$ cotransporter) (Sigma) was added at the final concentration of $100 \mu \mathrm{M} 10 \mathrm{~min}$ after forskolin addition. In both cases, there was a drop in the current and was stable after 1-3 min. Twenty-five microliters of the ethanol extract of each medicinal plant was then added on the serosal side at about 20 more min after ouabain or bumetanide addition.

\section{Statistical analyses}

Data are expressed as the mean \pm S.D. Comparisons among groups were performed by using one-way ANOVA. A difference of $P<0.05$ was considered statistically significant.

\section{Results}

\section{Qinpi}

Administration of the ethanol extract of Qinpi reduced the short circuit current of the forskolin-activated ileal epithelia. The decrease in current was $9.0 \pm 2.0 \mu \mathrm{A}$ (Table 1). Figure 1 shows that if ouabain was added before the ethanol extract of Qinpi, the decrease in current was $7.2 \pm 2.8 \mu \mathrm{A}$ (Table 2 ), which is not significantly different from that of adding Qinpi extract only. It seems that the effect of Qinpi extract on reducing the short circuit current is not influenced by the prior addition of ouabain. However, if bumetanide was added before the ethanol extract of Qinpi, the current reduction was attenuated to $3.0 \pm 2.0 \mu \mathrm{A}$ (Table 3 ); this value is significantly different from that of adding Qinpi extract only $(P=0.002)$. This shows that adding bumetanide before Qinpi extract diminishes the effect of Qinpi on reducing the short circuit current of the forskolin-activated ileal epithelia. 
Table 1. Changes in basal short circuit current induced by the ethanol extracts of three medicinal plants administered to rat ileal epithelia pretreated with forskolin

\begin{tabular}{lcccc}
\hline & Basal short circuit current & $\begin{array}{c}10 \text { min after the addition } \\
\text { of forskolin (a) }\end{array}$ & $\begin{array}{c}10 \text { min after the addition } \\
\text { of extract (b) }\end{array}$ & $\mathrm{b}-\mathrm{a}$ \\
\hline Qinpi (Fraxini cortex) & $35.5 \pm 11.4$ & $88.5 \pm 31.4$ & $80.4 \pm 30.5$ & $-9.0 \pm 2.0$ \\
Kushen (Sophora flavescens) & $52.3 \pm 1.7$ & $79.3 \pm 5.2$ & $73.3 \pm 5.4$ & $-5.7 \pm 1.7$ \\
Huanglian (Coptis teeta) & $58.7 \pm 21.7$ & $109.2 \pm 23.7$ & $95.7 \pm 25.8$ & $-13.5 \pm 8.4$ \\
\hline
\end{tabular}

Values represent means \pm S.D. $\mu \mathrm{A} / \mathrm{cm}^{2}$ for 6 individual measurements.

Table 2. Effect of oubain on the changes in basal short circuit current induced by the ethanol extracts of three medicinal plants administered to rat ileal epithelia pretreated with forskolin

\begin{tabular}{|c|c|c|c|c|c|}
\hline & $\begin{array}{c}\text { Basal short } \\
\text { circuit current }\end{array}$ & $\begin{array}{l}10 \text { min after } \\
\text { the addition } \\
\text { of forskolin }\end{array}$ & $\begin{array}{l}10 \text { min after } \\
\text { the addition } \\
\text { of ouabain (a) }\end{array}$ & $\begin{array}{l}10 \text { min after } \\
\text { the addition } \\
\text { of extract (b) }\end{array}$ & $\mathrm{b}-\mathrm{a}$ \\
\hline Qinpi (Fraxini cortex) & $58.0 \pm 3.9$ & $112.2 \pm 9.7$ & $83.2 \pm 10.2$ & $76.0 \pm 10.1$ & $-7.2 \pm 2.8$ \\
\hline Kushen (Sophora flavescens) & $55.7 \pm 8.0$ & $104.2 \pm 6.9$ & $74.3 \pm 14.8$ & $71.5 \pm 3.8$ & $-2.8 \pm 1.2$ \\
\hline Huanglian (Coptis teeta) & $49.0 \pm 10.3$ & $99.8 \pm 13.3$ & $75.2 \pm 16.2$ & $66.7 \pm 16.1$ & $-8.5 \pm 2.2$ \\
\hline
\end{tabular}

Values represent means \pm S.D. $\mu \mathrm{A} / \mathrm{cm}^{2}$ for 6 individual measurements.

Table 3. Effect of bumetanide on the changes in basal short circuit current induced by the ethanol extracts of three medicinal plants administered to rat ileal epithelia pretreated with forskolin

\begin{tabular}{|c|c|c|c|c|c|}
\hline & $\begin{array}{l}\text { Basal short } \\
\text { circuit current }\end{array}$ & $\begin{array}{l}10 \text { min after } \\
\text { the addition } \\
\text { of forskolin }\end{array}$ & $\begin{array}{c}10 \text { min after } \\
\text { the addition } \\
\text { of bumetanide (a) }\end{array}$ & $\begin{array}{l}10 \text { min after } \\
\text { the addition } \\
\text { of extract (b) }\end{array}$ & $\mathrm{b}-\mathrm{a}$ \\
\hline Qinpi (Fraxini cortex) & $52.7 \pm 13.7$ & $113.2 \pm 22.7$ & $76.8 \pm 23.9$ & $73.8 \pm 25.6$ & $-3.0 \pm 2.6$ \\
\hline Kushen (Sophora flavescens) & $49.3 \pm 10.0$ & $102.7 \pm 11.7$ & $64.7 \pm 11.8$ & $59.7 \pm 13.2$ & $-5.0 \pm 2.1$ \\
\hline Huanglian (Coptis teeta) & $53.6 \pm 6.9$ & $104.8 \pm 8.6$ & $77.7 \pm 11.9$ & $70.7 \pm 11.9$ & $-7.0 \pm 1.5$ \\
\hline
\end{tabular}

Values represent means \pm S.D. $\mu \mathrm{A} / \mathrm{cm}^{2}$ for 6 individual measurements.

\section{Kushen}

The extract of Kushen likewise could partially reduce the short circuit current of the forskolin-activated ileal epithelia. The decrease in current was $5.7 \pm 1.8 \mu \mathrm{A}$ (Table 1). Figure 2 shows that if ouabain was added before the ethanol extract of Kushen, the decrease in current was attenuated to $2.8 \pm 1.2 \mu \mathrm{A}$ (Table 2 ), and the value is significantly different $(P=0.03)$ from that of adding Kushen extract only (control). This indicates that adding ouabain before the Kushen extract blocks the effect of Kushen on reducing the short circuit current. On the contrary, the addition of bumetanide before the ethanol extract of Kushen had few effects on the reduction of current by the extract. This is because the decrease in current remains at $5.0 \pm 2.1 \mu \mathrm{A}$ (Table 3); the value is not significantly different from that of adding Kushen extract alone.

\section{Huanglian}

The ethanol extract of Huanglian reduced the short circuit current of the forskolin-activated ileal epithelia as well. The decrease of short circuit current by the ethanol extract of Huanglian in the forskolin-activated intestinal epithelia was $13.5 \pm 8.4 \mu \mathrm{A}$ (Table 1). Figure 3 shows that adding ouabain and bumetanide before the Huanglian extract both attenuate the effect of Huanglian on reducing the short circuit current. If ouabain was added before the ethanol extract of Huanglian, the decrease in current was $8.5 \pm 2.2 \mu \mathrm{A}$ (Table 2). Although this value is lower than that of adding Huanglian extract only, they are not significantly different from each other $(P=0.236)$. Adding bumetanide before the ethanol extract of Huanglian attenuated the current decrement to $7.0 \pm 1.5 \mu \mathrm{A}$ (Table 3 ). This value is also not significantly different $(P=0.101)$ compared to the current 


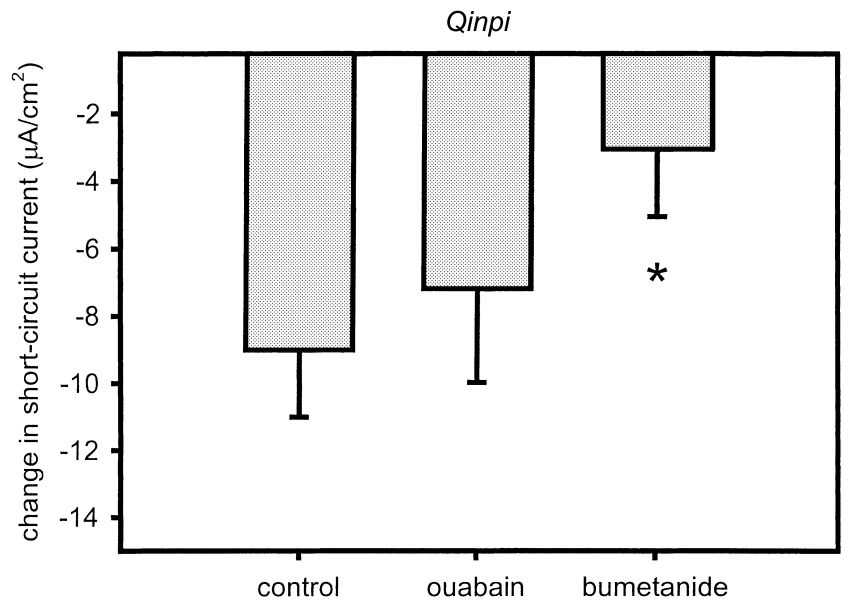

Fig. 1. Effect of oubain and bumetanide on the decrease in short circuit current induced by the ethanol extract of Qinpi. The current were measured across the forskolin-activated rat intestinal epithelia. Control: with Qinpi extract on the forskolin-activated ileal epithelia. Ouabain: with ouabain (final concentration of $100 \mu \mathrm{M}$ ) before the Qinpi extract on the forskolin-activated ileal epithelia. Bumetanide: with bumetanide (final concentration of $100 \mu \mathrm{M}$ ) before the Qinpi extract on the forskolin-activated ileal epithelia. Values represent means \pm S.D. for 6 individual measurements. Asterisk indicates a statistically significant difference $P<0.05$, as compared to the control by one way ANOVA.

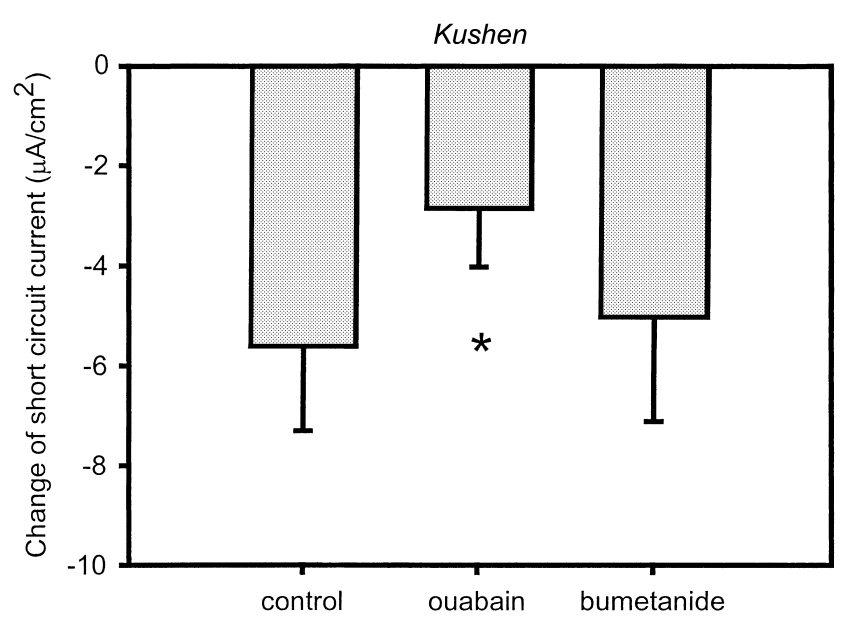

Fig. 2. Effect of ouabain and bumetanide on the decrease in short circuit current induced by the ethanol extract of Kushen. The current was measured across the forskolin-activated rat intestinal epithelia. Control: with Kushen extract on the forskolin-activated ileal epithelia. Ouabain: with ouabain (final concentration of $100 \mu \mathrm{M}$ ) before the Kushen extract on the forskolin-activated ileal epithelia. Bumetanide: with bumetanide (final concentration of $100 \mu \mathrm{M}$ ) before the Kushen extract on the forskolin-activated ileal epithelia. Values represent means \pm S.D. for 6 individual measurements. Asterisk indicates a statistically significant difference $P<0.05$, as compared to the control by one way ANOVA.

reduction generated by treatment of Huanglian extract alone.

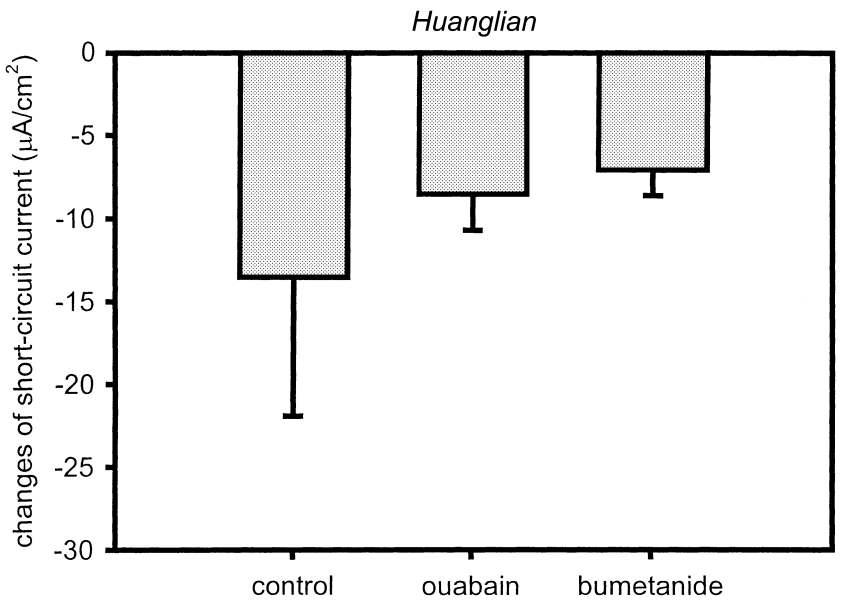

Fig. 3. Effect of ouabain and bumetanide on the decrease in short circuit current induced by the ethanol extract of Huanglian. The current was measured across the forskolin-activated rat intestinal epithelia. Control: with Huanglian extract on the forskolin-activated ileal epithelia. Ouabain: with ouabain (final concentration of $100 \mu \mathrm{M})$ before the Huanglian extract on the forskolin-activated ileal epithelia. Bumetanide: with bumetanide (final concentration of $100 \mu \mathrm{M}$ ) before the Huanglian extract on the forskolin-activated ileal epithelia. Values represent means \pm S.D. for 6 individual measurements.

\section{Discussion}

Qinpi, Kushen, and Huanglian are categorized as heat relief medicines in the Chinese medical literature (1). They are used to cure fever, diarrhea, and various inflammatory diseases. By using the Ussing chamber and voltage-current technique, this present study discerned the effects of these three Chinese medicinal plants with anti-diarrheal properties on ion transport of the rat intestinal epithelia. Our data reveal that the ethanol extracts of Qinpi, Kushen, and Huanglian could all reduce the short circuit current across the forskolinactivated rat ileal epithelia. Forskolin stimulates the production of cellular cyclic AMP and hence $\mathrm{Cl}^{-}$movement leading to elevation of short circuit current across the epithelia (14). Consequently, the results imply that extracts of the three plants may affect ion transport in the rat ileum epithelia, and this may be critical for their therapeutic effects as anti-diarrheal agents. It should be noted that the results of the present study are completely opposite to our study on other Chinese medicinal plants with laxative properties, namely, Dahuang (Rheum palmatum Linn.), Badou (Croton tiglium Linn.), and Huomaren (Cannabis sativa Linn.). Ethanol extracts of the three medicinal plants with laxative properties exert effects on augmenting the short circuit current of the forskolin-activated rat ileal epithelia (15). It seems that effects of these Chinese medicinal plants with anti- 
diarrheal and laxative properties on the short circuit current of the forskolin-activated rat ileal epithelia are totally different.

The effects of these three medicinal plants on $\mathrm{Na}^{+}$and $\mathrm{Cl}^{-}$transport were further studied by adding ouabain or bumetanide before treatment with the extracts. Ouabain inhibits the $\mathrm{Na}^{+}-\mathrm{K}^{+}$ATPase and hence blocks $\mathrm{Na}^{+}$ uptake, while bumetanide inhibits the $\mathrm{Na}^{+}-\mathrm{K}^{+}-2 \mathrm{Cl}^{-}$ cotransporter and then retards $\mathrm{Cl}^{-}$movement. The results of Qinpi show that the reducing effect of Qinpi extract on the short circuit current is not affected by ouabain, but affected by bumetanide. Since the Qinpi extract cannot reduce the current when the $\mathrm{Cl}^{-}$movement is inhibited by bumetanide, it is deduced that Qinpi extract may share a similar effect with the bumetanide; that is, Qinpi extract may have an effect on $\mathrm{Cl}^{-}$movement. On the contrary, the Qinpi extract can reduce the current despite the $\mathrm{Na}^{+}$movement being inhibited by ouabain; it hence is suggested that the Qinpi extract might not affect $\mathrm{Na}^{+}$movement, otherwise the current should not be reduced additionally after ouabain treatment.

The result of Kushen was contrary to the result of Qinpi. Treatment of ouabain prior to Kushen extract attenuated the decreasing effect of short circuit current caused by Kushen extract only on the forskolin-activated rat ileal epithelia. Nonetheless, Kushen extract decreases the short circuit current further despite adding bumetanide before the extract. The results would indicate that the ethanol extract of Kushen affects $\mathrm{Na}^{+}$ movement rather than $\mathrm{Cl}^{-}$movement. Reduction of the short circuit current by Kushen is attributed to its modification of $\mathrm{Na}^{+}$transport.

The data of Huanglian was different to that of the previous two medicinal plants. Neither ouabain nor bumetanide could significantly attenuate the effect on decreasing the short circuit current by the Huanglian extract on the forskolin-activated rat ileal epithelia. It hence is suggested that ethanol extract of Huanglian may not affect $\mathrm{Na}^{+}$or $\mathrm{Cl}^{-}$movement. Reduction of the short circuit current by Huanglian could be ions other than $\mathrm{Na}^{+}$or $\mathrm{Cl}^{-}$.

Ingredients of the three plants have been studied in many studies (1); however, most of the studies do not provide evidence for supporting their effects on epithelial transport. Instead, these studies indicate that many constituents of the three medicinal plants are effective in anti-inflammation and anti-microorganisms (1). Qinpi extract contains fraxetin, esculetin, and other substances (1). The esculetin was reported to inhibit 5'lipoxygenase and leukotriene biosynthesis (16). Kushen contains mainly alkaloids such as matrine and sophoridine (1). Huanglian also contains various alkaloids including berberine (1). The berberine alone may exert an anti-secreting action on intestinal epithelial cells by affecting $\mathrm{K}^{+}$channels (17) and may block $\mathrm{Ca}^{2+}$ influx in the smooth muscle cells of guinea pig colon (18). This could moderately explain why the ethanol extract of Huanglian does not affect $\mathrm{Na}^{+}$or $\mathrm{Cl}^{-}$movement in this present study.

It should be noted that addition of ethanol extracts of these plants on the mucosal side did not affect the current like the addition of these extracts on the serosal side did (data not shown). They influence the current in the forskolin-activated rat ileal epithelia when added on the serosal side. In this regard, these plant extracts might not act on channel or transporter on the apical membrane of the ileal epithelial cells. In addition, these extracts showed insignificant effect on the short circuit current on the rest of the rat ileal epithelia (data not shown). Therefore, they may not act directly on the $\mathrm{Na}^{+}-\mathrm{K}^{+}$ ATPase or $\mathrm{Na}^{+}-\mathrm{K}^{+}-2 \mathrm{Cl}^{-}$cotransporter located on the basolateral membrane of the epithelial cells.

The intestinal epithelial cells may respond to many effectors molecules and hence change the ion movements. In those reactions, many cellular components participate in the molecular events that occur outside the cells, through the cell, and finally to the ion transport apparatus on the cell membrane. In cholera-induced diarrhea, the cholera toxin stimulates the $G$ protein on the membrane of the intestinal epithelial cells, elicits signal transduction leading to $\mathrm{Cl}^{-}$movement from the serosa to the mucosa, and hence water secretion into the intestine lumen $(19-21)$. Besides cholera-induced diarrhea, there are other types of diarrhea that result from perturbation of ion and water movements in different ways. Inflammation, taken as an example, is frequently combined with diarrhea in the intestinal tissues. This could be seen in the case of the lipopolysaccharide (LPS) of the Gram-negative bacteria $(22,23)$. The LPS stimulates the immunocytes or the neural cells in the intestinal wall to produce nitric oxide or prostaglandin, and these two molecules are involved in various cases of diarrhea $(24-28)$. Other than nitric oxide or prostaglandin, the immunocytes secrete many cytokines in the inflammatory tissues. Evidences show that pro-inflammatory cytokines, such as interleukin (IL)-1 and IL-3, stimulate $\mathrm{Cl}^{-}$secretion $(29,30)$, while anti-inflammatory cytokines IL-4, IL-10, and IL-13 promote intestinal uptake of $\mathrm{Na}^{+}$and $\mathrm{Cl}^{-}(31,32)$.

The effect on ion transport of intestinal epithelia is seen in other medicinal plants with anti-diarrheal properties. TJ-14 extracted from Hange-Shashin-To, a compound solution prepared from several Chinese medicinal plants including Huanglian, is reported to inhibit diarrhea (33). TJ-14 was also shown to inhibit water secretion caused by cholera toxin $(34,35)$. SP-303 
derived from latex of the plant Croton lechleri, from South America, also has an effect on reducing the forskolin-stimulated $\mathrm{Cl}^{-}$current (36). The present study proves that ethanol extracts of Qinpi, Kushen, and Huanglian can reduce the short circuit current across the forskolin-activated rat ileal epithelia by affecting $\mathrm{Na}^{+}, \mathrm{Cl}^{-}$, or other ion movements in the rat intestinal epithelia. Nevertheless, these extracts might not act directly on the ion transport apparatus, but likely act through immune or inflammatory pathways. Further study will be needed to distinguish the molecular action in the intestinal epithelia elicited by these Chinese medicinal plants.

\section{Acknowledgments}

This study was supported by a grant to J.C. Tsai and W.C. Chang from the National Science Council, Taiwan (NSC90-2320-B-018-002) and by a grant from China Medical University (CMC90-M-02).

\section{References}

1 Yen CH. The pharmacology of Chinese plants. 1st. Taipei: ChinYin Publishing; 1994. p. 160-225. (text in Chinese)

2 Powell DW, Binder HJ, Curran PF. Electrolyte secretion by the guinea pig ileum in vitro. Am J Physiol. 1972;223:531-537.

3 Fondacaro JD. Intestinal ion transport and diarrheal disease. Am J Physiol. 1986;250;G1-G8.

4 Rabbani GH, Greenough WB. Textbook of secretory diarrhea. Lebenthal E, Duffey ME, editors. New York: Raven Press; 1990. p. 233-255.

5 Schultz SG, Frizzell RA. An overview of intestinal absorptive and secretory processes. Gastroenterology. 1972;63:161-170.

6 Hawker PC, Mashiter KE, Turnberg LA. Mechanisms of transport of $\mathrm{Na}, \mathrm{Cl}$, and $\mathrm{K}$ in the human colon. Gastroenterology. 1978;74:1241-1247.

7 Holtug K, Hansen MB, Skadhauge E. Experimental studies of intestinal ion and water transport. Scand J Gastroenterol. 1996; 31 Suppl 216:95-110.

8 Davidson GP, Gall DG, Pertic M, Butler DG, Hamilton JR. Human rotavirus enteritis induced in conventional piglets. Intestinal structure and transport. J Clin Invest. 1977;60:1402-1409.

9 McEwan GT, Schousboe B, Skadhauge E. Effect of antisecretory factor on Escherichia coli STs enterotoxin-induced alkalinisation of pig. Pflugers Arch. 1990;417:174-179.

10 Osman NE, Westrom B, Karlsson B. Serosal but not mucosal endotoxin exposure increases intestinal permeability in vitro in the rat. Scand J Gastroenterol. 1998;33:1170-1174.

11 Starkey WG, Candy DC, Thornber D, et al. An in vitro model to study aspects of the pathophysiology of murine rotavirusinduced diarrhea. J Pediatr Gastroenterol Nutr. 1990;10:361370.

12 Field M, Fromm D, Mccoll I. Ion transport in rabbit ileal mucosa. I. Na and $\mathrm{Cl}$ fluxes and short circuit current. Am J Physiol. 1971;220:1388-1396.

13 Kurkchubasche AG, Cardona M, Watkins SC, et al. Trans- mucosal passage of bacteria across rat intestinal epithelium in the Ussing Chamber: effect of nutritional factors and bacterial virulence. Shock. 1998;9:121-127.

14 Sharp GWG, Hynie S. Stimulation of intestinal adenyl cyclase by cholera toxin. Nature. 1971;229:266-269.

15 Tsai JC, Tsai S, Chang WC. Effect of ethanol extracts of three Chinese medicinal plants with laxative properties on ion transport of the rat intestinal epithelia. Biol Pharm Bull. In press.

16 Neichi T, Koshihara Y, Murota S. Inhibitory effect of esculetin on 5-lipoxygenase and leukotriene biosynthesis. Biochim Biophys Acta. 1983;753:130-132.

17 Taylor CT, Winter DC, Skelly MM, et al. Berberine inhibits ion transport in human colonic epithelia. Eur J Pharmacol. 1999; 368:111-118.

18 Cao JW, Luo HS, Yu BP, Huang XD, Sheng ZX, Yu JP. Effects of berberine on intracellular free calcium in smooth muscle cells of guinea pig colon. Digestion. 2001;64:179-183.

19 Kimberg DV, Field M, Johnson J, Henderson A, Gershon E. Stimulation of intestinal mucosal adenyl cyclase by cholera enterotoxin and prostaglandins. J Clin Invest. 1971;50:12181230.

20 Petritsch W, Eherer AJ, Holzer-Petsche U, Hinterleitner TA, Beubler E, Krejs GJ. Effect of cholera toxin on the human jejunum. 1992;33:1174-1178.

21 Jodal M, Holmgren S, Lundgren O, Sjoqvist A. Involvement of the myenteric plexus in the cholera toxin induced net fluid secretion in the rat small intestine. Gastroenterology. 1993; 105:1286-1293.

22 Lundgren $\mathrm{O}$, Jodal M. The enteric nervous system and cholera toxin-induced secretion. Comp Biochem Physiol. 1997;118A: 319-329.

23 Goyal RK, Hirano I. The enteric nervous system. N Engl J Med. 1996;334:1106-1115.

24 Brunsson I, Sjotlqvist A, Jodal M, Lundgren O. Mechanisms underlying the small intestinal fluid secretion caused by arachidonic acid, prostaglandin E1 and prostaglandin E2 in the rat in vivo. Acta Physiol Scand. 1987;130:633-642.

25 Pugin J, Schurer-Maly CC, Leturcq D, Moriarty A, Ulevitch RJ, Tobias PS. Lipopolysaccharide activation of human endothelial and epithelial cells is mediated by lipopolysaccharide-binding protein and soluble CD14. Proc Natl Acad Sci USA. 1993; 90:2744-2748.

26 Konturek PH. Involvement of nitric oxide and prostaglandin in gastroprotection induced by bacterial lipopolysacharide. Scand J Gastroenterol. 1998;33:691-700.

27 Izzo AA, Mascolo N, Capasso F. Nitric oxide as a modulator of intestinal water and electrolyte transport. Digest Dis Sci. 1998; 43:1605-1620.

28 Greenwood-Van Meerveld B, Tyler K, Keith JC Jr. Recombinant human interleukin-11 modulates ion transport and mucosal inflammation in the small intestine and colon. Lab Invest. 2000;80:1269-1280.

29 Chiossone DC, Simon PL, Smith PL. Interleukin-1: effect on rabbit ileal mucosal ion transport in vitro. Eur $\mathrm{J}$ Pharmacol. 1990;180:217-228.

30 Theodorou V, Eutamene H, Fioramonti J, Junien JL, Bueno L. Interleukin-1 induces a neurally mediated colonic secretion in rats: involvement of mast cells and prostaglandins. Gastroenterology. 1994;106:1493-1500.

31 Madsen KL, Tavernini MM, Mosmann TR, Fedorak RN. Inter- 
leukin 10 modulates ion transport in rats small intestine. Gastroenterology. 1996;111:936-944.

32 Zund G, Madara JL, Dzus AL, Awtrey CS, Colgan SP. Interleukin-4 and Interleukin-13 differentially regulate epithelial chloride secretion. J Biol Chem. 1996;271:7460-7464

33 Kawagoe H. Pharmacological studies on antidiarrheal effects of Hange-Shashin-To. J Clin Rehabil. 1994;3:1058-1059.

34 Kase Y, Hayakawa T, Takeda S, Ishige A, Aburada M, Okada M. Pharmacological studies on antidiarrheal effects of Hange- shashin-to. Biol Pharm Bull. 1996;19:1367-1370.

35 Kase Y, Hayakawa T, Takeda S, Ishige A, Aburada M, Okada M. Effects of Keishi-ka-shakuyaku-to (Gui-Zhi-Jia-Shao-YaoTang) on diarrhea and small intestinal movement. Biol Pharm Bull. 1998;22:87-89.

36 Gabriel SE, Davenport SE, Steagall RJ, Vimal V, Carlson T, Rozhon EJ. A novel plant-derived inhibitor of cAMP-mediated fluid and chloride secretion. Am J Physiol. 1999;276:G58-G63. 